\title{
TELEVISION RESHAPED BY BIG DATA: IMPACTS AND IMPLICATIONS FOR NETFLIX-LIKE PLATFORMS IN THE AGE OF DATAISM
}

\section{CÉLIA QUICO*}

\begin{abstract}
Television was born analogue, almost 100 years ago: first broadcast across airwaves, then delivered via analogue cable and satellite, to reach millions and millions of people around the world. Like many other industries, television has been under the process of digital transformation, integrating digital technologies in all parts of its value chain, from content production to content distribution. Today, inseparable from the digital transformation process is the large, diverse and ever-growing volume of data created, captured, analyzed and applied - also known as Big Data. Television is being reshaped by Big Data, with newcomers to the industry such as Netflix leading the way, for others to follow - and for others to fail. The concepts of Platform Capitalism, Surveillance Capitalism and Dataism may illuminate many of the challenges faced by the main stakeholders in the television industry, with implications that go much beyond this field. Lastly, Netflix's impact on the production, distribution and consumption of audiovisual content is still to be understood in a small market such as Portugal: the current exploratory paper is also meant to be the basis of future research in Portugal about internet-distributed television.
\end{abstract}




\section{Television - from analogue to digital and beyond}

Netflix, Amazon, YouTube and Apple are major global players in the distribution of audiovisual content to consumers - and even audiovisual production, as is the case for Netflix and Amazon. If we go back to 1999, that was not the case: in about 20 years, the TV landscape has changed quite significantly, with national players being challenged by these new global intermediaries.

Invented in the late 1920s, the audiovisual broadcast technology we call television was quickly diffused and adopted in most countries after the World War II. Radio spectrum scarcity was the technical reason provided for States to have strict management of the airwaves - the first delivery technology to distribute a TV signal. Concurrent distribution systems from terrestrial television would become available, namely cable and satellite, from the 1950s to the 1990s. The transition from analogue TV to digital TV would first start with the satellite and cable platforms in the mid-1990s, while terrestrial TV switchover is still taking place in many countries. In the late 1990s and early 2000s, internet also became a distribution channel for TV content, with pay-TV operators starting to offer IPTV (Internet Protocol Television) to their customers.

However, at the time, in parallel with the very significant increase in TV channels delivered via the traditional distribution technologies - terrestrial, cable, satellite -, internet access and use were exploding worldwide. Bandwidth limitations of the internet were gradually overcome and in the early 2000s it became possible to watch or download video content online with reasonable quality. Then, YouTube came onto the scene in 2004, and shortly after, in late 2006, it would be bought by Google, in one of the biggest acquisitions ever in this industry to the present day. Also, significantly, other new players were making their own path in this already overcrowded market. Particularly since 2010, the so-called Over-The-Top (OTT) television services came onto the market, a term that distinguishes a new way to provide television content, going "over" or by-passing the traditional cable, satellite and terrestrial TV services (Lotz, 2017). The definition of Subscription Video-on-Demand (SVoD) services is similar to OTT television, referring to a service that allows users to access a large range of video content for a monthly rate fee. The quick popularity of such OTT or SVoD services in the US - such as Netflix and Amazon led to a significant number of pay-TV subscribers cancelling their subscriptions, a consumer trend named "cord-cutting": a Nilsen study (2019) estimated that 16 million homes in the US no longer have traditional pay-TV subscriptions, relying exclusively on OTT services or free-to-air terrestrial TV. Rather than using the acronyms OTT television or SVoD for services such as Netflix, here the preference is for the term internet-distributed television, defined by Amanda Lotz (2017) as professionally produced content is circulated and consumed through websites, online services, platforms and apps, rather than broadcast, cable, or satellite systems. The major advantage of such services for the audiences are, as observed by Lotz (2017), the personalised viewing of content independent of a schedule, enabling a non-linear consumption of individual content, in contrast with linear TV provided by the traditional TV operators.

\section{Netflix - from DVD rental to video content streamer and TV producer}

In 1997, Netflix started an alternative service to video rental stores in the US, by providing a monthly-subscription model, using mail-delivery to distribute video content in a DVD format. Today, Netflix is a global cinema and TV streaming platform, the biggest video-streaming service in the world, with over 148 million paid subscribers, which represents nearly 30 percent of total streaming video subscriptions worldwide, as of April 2019 (Molla, 2019). Netflix is available almost everywhere, in more than 190 countries - with the exceptions of China, North Korea, Syria and Crimea (Lobato, 2019). 
Netflix has become much more than a mere content distributor: particularly in the US, where 60.2 million people subscribe to Netflix (Pallotta, 2019), it has become part of a life-style choice, for instance with the expression "Netflix and chill" becoming popular mostly among young people, as a coded message for watching Netflix together and having - let's say - intimate moments together. Grandiose claims attached to Netflix's impact both on the industry and on society at large can range from excitement: "Netflix is revolutionizing the way people watch films" (Buchanan, 2019) or "It's a way of life, a utility, a universally understood medium" (Sims, 2019), to concern: "Netflix is addictive" or "Netflix is American Cultural Imperialism" (Tait, op. cit. Vlessing, 2019). Central to the success of Netflix are two core developments - discovery and access to video content, plus capturing, analysing and applying viewer data, notes Hesmondhalgh (2019), for whom these are two key recent developments in television: "increasing battles over prominence and discoverability in a newly abundant video landscape; and the collection, analysis and exchange of viewer data by businesses". For Hesmondhalgh (2019), today television industry needs to be understood as a complex ecosystem: "not as a single industry under threat from Silicon valley but as a medium that emerges from complex interactions between interlocked industries, technologies and regulations".

The investment on original and exclusive content is responsible for the enormous amount of debt accumulated by Netflix over the last few years, as observed by Bilton (2019): "While the company generates $\$ 1.4$ billion a month from its users, Netflix has also borrowed more than $\$ 8$ billion to create original content. (The company has existing debt of about $\$ 11.8$ billion)". Other major players are positioning themselves for a piece of the internet-distributed television market, particularly Disney, WarnerMedia and Apple (Bilton, 2019). So far, Netflix has no competition in this field, not only from the traditional pay-TV operators, as the other internet-distributed television services, such as Amazon and Hulu. Also, importantly, the data Netflix owns allows the company to know with a high degree of probability which new content will succeed among their subscribers (Madrigal, 2014). And so far, Netflix has claimed that it has not sold its data to advertisers or other interested organisations, as the CEO and founder Reed Hastings stated: "We don't import any data, so we're completely secure, isolated, just the data that helps us serve our members ever better" (Bilton, 2019). Whether Netflix maintains this no-sharing or no-selling data policy is yet to be seen.

\section{Big Data - capturing, analysing, predicting and influencing consumer behaviour}

"The combination of this data with cutting edge analytical techniques ... makes Netflix a true Big Data company", observes Bernard Marr (2015), noting that what makes Netflix stand out from its competitors - "the Holy Grail" - is the capability to predict what the customers will enjoy watching Inspired by Amazon's recommendation engine, Netflix has invested massively in perfecting their algorithm to keep customers happy in their "walled garden", to reuse an old pay-TV term from the late 1990s for the early 2000s.

Broadcast programming and video portal curation are quite different activities, as notes Lotz (2017), and even if internet distribution requires the organisation of content for delivery, the framework is quite different: "I use "portal" to distinguish the crucial intermediary services that collect, curate, and distribute television programming via internet distribution".

Netflix, Amazon Video, Hulu, HBO Now are portals: entry points to online libraries of curated contents. A key difference between TV channels and portals is the interface, which in the case of portals becomes even a distinctive part of the user experience, perhaps almost as important as the content 
itself for the user. Lotz notes (2017) that the experience of using Netflix differs from other concurrent portals such as HBO Now, "not just the programming, but also viewers' experience distinguishes portals to make portal features part of product differentiation".

Another key difference is the logic of media production: in the case of TV channels, these are mostly dependent on advertising revenues, while portals are based on a subscription model. Lotz revisits (2017) Bernard Miége's categorisation of cultural production, who proposed three models: the publishing model, the flow model, and the written press model. In particular, Miége defines the flow model as essentially a continuous flow of the cultural goods produced and its corresponding integration in daily life, characteristic of radio and television (Lotz, 2017). Content scarcity and content scheduling are basic elements of the flow model, notes Miége, requiring programme planners to schedule the content flow, to maximise exposure to audiences: the "flow industries" produce a schedule rather than content.

Internet-distributed television like Netflix does not conform to the flow model, or the publishing model and the written press model, argues Lotz (2017), even if these portals replicate some of the linear or "flow-like" features, such as auto-play. Lotz proposes a new category, the subscriber model, which is characterised by a user - individual or household - paying a fee for accessing a library of cultural goods. For portals operating within the subscriber model, their central task is to "curate a collection of cultural goods such that curating involve both compiling content and organizing it in a convenient and accessible manner" (Lotz, 2017).

However, before the interface, there is the infrastructure. In the case of Netflix, the quality of data is crucial: to start with, the data which describes the content - the meta-data. Netflix has a team of people specially trained to watch video content - a.k.a. "Netflix taggers" - , in order to tag them with relevant and efficient descriptors, leading to thousands and thousands of micro-genres: "This process is so sophisticated and precise that taggers receive a 36-page training document that teaches them how to rate movies on their sexually suggestive content, goriness, romance levels, and even narrative elements like plot conclusiveness" (Madrigal, 2014).

After capturing the different content attributes in the best way possible, these tags are then combined with another data-set: Netflix users' viewing behaviour, hence becoming the foundation of the company's competitive advantage (Madrigal, 2014). The recommendation system Netflix has built draws into other similar systems, such as Amazon or Facebook NewsFeed. However, Netflix goes further, having identified over 2,000 "taste communities" (Nguyen, 2018), which then lead to the content personalisation for each Netflix user homepage.

However, the efficiency of the Netflix recommendation system may come with a downside, for the users, at least. As Netflix becomes better at predicting what each viewer may want to see, most likely it will provide content recommendations which reinforce those implied tastes, rather than expand someone's taste range. This process may contribute to the co-called "filter-bubble" effect, defined by Eli Pariser (2011) as a "personal ecosystem of information that's been catered by these algorithms to who they think you are". The old way of TV viewing by zapping through TV channels perhaps gives a person a better chance to find something unexpected - and even mind-opening.

Also concerning is the fact that Netflix and similar platforms seem to be designed for compulsive consumption, namely by proving the full access to full series, enabling and reinforcing a TV consumption behaviour known as "binge-watching", which in extreme cases is corelated with higher levels 
of stress, anxiety and depression, when compared with nonbinge-watching (Page, 2017).

\section{Digital transformation critique - Platform Capitalism and Surveillance Capitalism}

"In the twenty-first century, on the basis of changes in digital technologies, data has become increasingly central to firms and their relations with workers, customers, and other capitalists", states Nick Srnicek (2016, p. 6). TV industry is no exception to this global trend, with newcomers challenging the traditional stakeholders. "The platform has emerged as a new business model", argues Srnicek (2016, p. 5), stating further that we are witnessing the rise of large monopolistic corporations, which extract and control large amounts of data.

The term "Platform Capitalism" was coined by Srnicek to designate this new stage of Capitalism. But what are platforms? According to Srnicek (2016, p. 23) platforms are basically "digital infrastructures that enable two or more groups to interact". Platforms are intermediaries, that bring together different types of users, by providing infrastructures and designing core architecture that governs the interaction possibilities. These new kind of firms, notes Srnicek (2016, p. 26) display "monopoly tendencies driven by network effects, by employing cross-subsidisation to draw in different user groups". Data is the new oil, observes Srnicek (2016, p. 23), and like oil, data are a material "to be extracted, refined, and used in a variety of ways. The more data one has, the more uses one can make of them". The new ruling class has ownership over information, rather than owning the means of production (Srnicek, 2016). As consumers, Nick Srnicek notes (2016, p. 3) "we are presented with a cornucopia of on-demand services and with the promise of a network of connected devices that cater to our every whim". However, this promise has a high price to be paid by consumers: loss of privacy, with almost constant surveillance. Srnicek argues that there is a convergence of surveillance and profit making in the digital economy, leading some to speak of 'surveillance capitalism'. Shoshana Zuboff (2015) coined this term to describe a new form of information capitalism which "aims to predict and modify human behavior as a means to produce revenue and market control". Zuboff (2015, p. 82) goes further than Srmicek by arguing that if power in the past was identified with the means of production ownership, in our days, power is "identified with ownership of the means of behavioral modification". Recognising that Big Data may be used in several ways, Zuboff (2015, p. 75) points out that we are witnessing a sort of paradigm shift, from the logic of industrial capitalism to the logic of surveillance capitalism, in which the Big Brother becomes the Big Other, the latter being "constituted by unexpected and often illegible mechanisms of extraction, commodification, and control that effectively exile persons from their own behavior while producing new markets of behavioral prediction and modification". Surveillance capitalism goes beyond market capitalism and challenges democratic norms, Zuboff warns.

\section{Conclusion - towards Dataism?}

Overall, the TV industry is going through a major transformation, in which the traditional operators are being overrun by newcomers, mostly coming from information and the communication technologies sector, bringing new pressures to an already under-pressure industry. The public service television guidelines, "to entertain, inform and educate" the viewers, are being substituted by another regime, in which supposedly the "consumer is king". Supposedly, the platforms are just giving the consumers what they want, even before they - we - know. The algorithm observes all, knows all, decides all, so it seems.

The authority of algorithms and Big Data is also known as Dataism, a term popularised by Yuval Noah Harari in his book Homo Deus. Harari (2016) argues that "just as free-market capitalists believe in the invisible hand of the market, so Dataists believe in the invisible hand of the dataflow. As 
the global data-processing system becomes all-knowing and all-powerful, so connecting to the system becomes the source of all meaning".

However, algorithms are not all equal and the diversity of purposes that algorithms have today can range from saving human lives, to support the more ordinary action of viewing TV and movies. Rather than worshiping or demonising algorithms, to understand its logic and its ideology it is required that: "As long as you have greater insight and self-knowledge than the algorithms, your choices will still be superior and you will keep at least some authority in your hands" (Harari, 2016). As such, the insights of thinkers such as Hanna Arendt (1958, p. 171) may shed light on this nebulous world: "The question therefore is not so much whether we are the masters or the slaves of our machines, but whether machines still serve the world and its things, or if, on the contrary, they and the automatic motion of their processes have begun to rule and even destroy the world and things".

\section{Appendix: for a brief history of Netflix in Portugal}

Netflix arrived in Portugal in late 2015: ever since, it is assumed that the number of subscribers has been growing steadily, but so far the company has not provided exact figures for Portugal (Carvalho, 2019). However, interesting qualitative information was given by Yann Lafargue, Netflix communication director in Europe (cit. Cardoso \& Baldi, 2018), about major trends in terms of Portuguese Netflix consumers, namely that in 2018 about two thirds of these users watched Netflix outside their homes, in public spaces such as restaurants and on public transportation. Cardoso and Baldi (2018) provide some elements about the national SVoD market size, based upon Digital Market Outlook Statista and Instituto Nacional de Estatística (INE), which they estimate to be 6.54 million Euros. The penetration rate of SVoD in Portugal reached 3.6\% in 2018 according to Market Outlook
Statista, while INE indicated a 5\% penetration rate in 2016. Marktest barometer of telecommunication indicates a $2.3 \%$ penetration rate achieved in the $3^{\text {rd }}$ trimester of 2016 and $5.5 \%$ achieved during 2017's $3^{\text {rd }}$ trimester (Cardoso \& Baldi, 2018). As Netflix expands their customer base outside the US, the probability of producing in other countries may also increase. However, even if Netflix claims that since 2015 to 2019 their catalogue has grown five times in Portugal, so far the company has not produced a single original piece of content in the country. Yann Lafargue claims that Netflix will launch over 100 European productions on their platform (Carvalho, 2019), but so far, no information has been made public about the production of a Portuguese series, film or documentary by this global platform.

The lack of Portuguese produced content can be seen as disappointing for some of the main stakeholders in the TV industry in Portugal, namely for TV and film producers and, also, for Portuguese TV audiences. For the major Portuguese TV channels this is mostly good news, since it will allow them to keep a distinctive and exclusive offer of their portfolio. In theory, Netflix could bring new opportunities for major TV channels in Portugal - namely media groups such as Media Capital and Grupo Impresa -, allowing for the distribution of their proprietary content, since some of these media groups already export content for a few international markets, such as the Portuguese telenovelas. Independent TV and film producers could also benefit from Netflix investment in the production of Portuguese content, reaching global audiences almost instantly and quite effectively. Regarding the Portuguese TV audiences, Netflix provides their customers with a reasonably priced alternative to linear $\mathrm{TV}$, with the convenience of accessing an extensive library of contents, available anytime and anywhere and on any device, via a user-friendly interface.

However, Netflix may also bring a new set of risks for these main stakeholders in the TV industry in Portugal. The major 
TV channels have already been losing audiences for years in a row, first with the multi-channel explosion and then with the increased use of the internet (in particular, competition from social media such as Facebook and online video platforms such as YouTube). Independent TV and film producers face other risks, as TV channels in Portugal may become more defensive and outsource fewer productions, downgrading both the quantity and quality of content made in Portugal. And for the Portuguese TV audiences there is the risk of having a TV diet with basically US content, with no local production which reflects Portuguese society and culture. Also, the less affluent people may not have the chance to subscribe to such kinds of services, which on top require an internet subscription. These and other questions require empirical studies, to better understand the impact and implications of Netflix and concurrent services in a country such as Portugal.

\section{References}

Arendt, H. (1958-1998), The Human Condition. Chicago, IL: University of Chicago Press.

Bilton, N. (2019), "We Don't Have Any Advertising, So We Don't Sell Any Data": Can Netflix Take Over the World Without Turning Evil? Retrieved from: https://www.vanityfair.com/ news/2019/03/can-netflix-take-over-the-world-without-turning-evil Last access date: 2019-11-11

Buchanan, K. (2019, June 20), How Will the Movies (As We Know Them) Survive the Next 10 Years? Retrieved from: https://www.nytimes.com/interactive/2019/06/20/movies/ movie-industry-future.html Last access date: 2019-11-11.

Cardoso, G. \& Baldi, V. (2018), SVod - Subscription Video on Demand - Mercado, prospectivas e cenários de futuro para Portugal. Lisboa: Obercom.

Carvalho, C.L. (2019, July 18), Netflix: originais portugueses? "Vai acontecer em determinada altura". Retrieved from: https://www.timeout.pt/lisboa/pt/noticias/netflix-originais-portugueses-vai-acontecer-em-determinada-altura-071518 Last access date: 2019-11-11.

Harari, Y.N. (2016, August 26), Yuval Noah Harari on big data, Google and the end of free will. Retrieved from: https://www. ft.com/content/50bb4830-6a4c-11 e6-ae5b-a7cc5dd5a28c Last access date: 2019-11-11.

Hesmondhalgh, D. (2019), "Television device ecologies, prominence and datafication: the neglected importance of the set-top box". Media, Culture and Society, 47(7), 958-974. DOI: https://doi.org/10.1177/0163443719857615 Last access date: 2019-11-15. 
Lobato, R. (2019). Netflix Nations: The Geography of Digital Distribution. New York: NYU Press.

Lotz, A. D. (2017), Portals: A Treatise on Internet-Distributed Television. Ann Arbor, MI: Michigan Publishing, University of Michigan Library. DOI: http://dx.doi.org/10.3998/mpub.9699689.

Madrigal, A.C. (2014, January 2), How Netflix Reverse-Engineered Hollywood. Retrieved from: https://www.theatlantic. com/technology/archive/2014/01/how-netflix-reverse-engineered-hollywood/282679/ Last access date: 2019-11-11.

Marr, B. (2015, April 22), Big Data: How Netflix Uses It to Drive Business Success. Retrieved from: https://www.smartdatacollective.com/big-data-how-netflix-uses-it-drive-business-success/ Last access date: 2019-11-11.

Molla, R. (2019, April 16), Netflix makes up nearly 30 percent of global streaming video subscriptions. Retrieved from: https://www.vox.com/2019/4/16/18410556/netflix-30-percent-global-streaming-video-subscriptions-q1-2019 Last access date: 2019-11-11.

Nielsen Company (2019, January 31), How the Growth and Evolution of the Over-the-Air TV Home Fits Into Today's Viewing Landscape. Retrieved from: https://www.nielsen.com/ us/en/insights/article/2019/how-the-growth-and-evolutionof-the-over-the-air-tv-home-fits-into-media-landscape/ Last access date: 2019-11-11.

Nguyen, N. (2018, December 13), Netflix Wants to Change The What You Chill. Retrieved from: https://www.buzzfeednews.com/article/nicolenguyen/netflix-recommendation-algorithm-explained-binge-watching Last access date: 201911-11.
Page, D. (2017, November 4), What happens to your brain when you binge-watch a TV series? Retrieved from: https:// www.nbcnews.com/better/health/what-happens-your-brainwhen-you-binge-watch-tv-series-ncna816991 Last access date: 2019-11-11.

Pallotta, F. (2019, April 17), Netflix added record number of subscribers, but warns of tougher times ahead. Retrieved from: https://edition.cnn.com/2019/04/16/media/netflixearnings-2019-first-quarter/index.html Last access date: 2019-11-11.

Pariser, E. (2011), The Filter Bubble: What the Internet Is Hiding from You. New York: Penguin Press.

Sims, D. (2019, June 29), Netflix Is a Business, Not a Movement. Retrieved from: https://www.theatlantic.com/entertainment/archive/2019/06/netflix-business-not-movement/592402/ Last access date: 2019-11-11.

Srnicek, N. (2016). Platform Capitalism. John Wiley \& Sons.

Vlessing, E. (2019, January 31), Canadian TV Boss Accuses Netflix of "Imperialism". Retrieved from: https://www.hollywoodreporter.com/news/canadian-tv-boss-accuses-netflix-imperialism-1181810 Last access date: 2019-11-11.

Zuboff, S. (2015), Big Other: surveillance capitalism and prospects of an information civilization. Journal of Information Technology 30, pp. 75-89. DOI:10.1057/jit.2015.5. 